\title{
Rheological and thermal performance of newly developed binder systems for ceramic injection molding
}

Conference Paper · May 2016

DOI: $10.1063 / 1.4949695$

CITATIONS

0

3 authors, including:

\section{Berenika Hausnerova}

Tomas Bata University in Zlín

94 PUBLICATIONS 399 CITATIONS

SEE PROFILE
READS

42

Eva Hnátková

Tomas Bata University in Zlín

12 PUBLICATIONS 6 CITATIONS

SEE PROFILE 


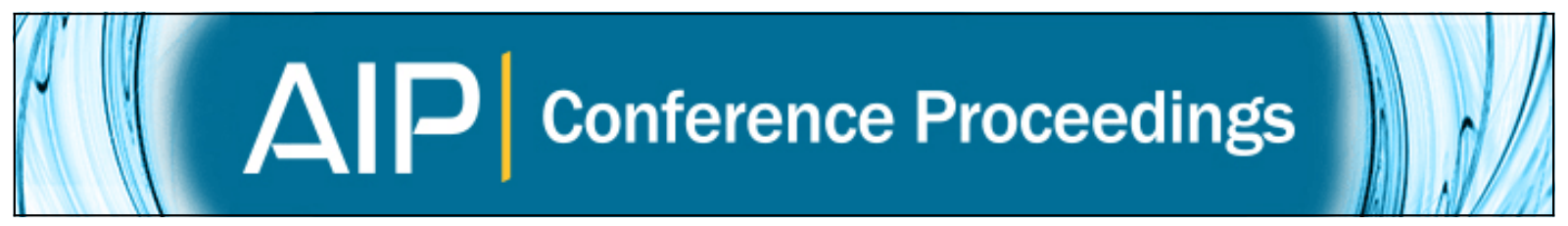

Rheological and thermal performance of newly developed binder systems for ceramic injection molding

Berenika Hausnerova, Vera Kasparkova, and Eva Hnatkova

Citation: AIP Conference Proceedings 1736, 020120 (2016); doi: 10.1063/1.4949695

View online: http://dx.doi.org/10.1063/1.4949695

View Table of Contents: http://scitation.aip.org/content/aip/proceeding/aipcp/1736?ver=pdfcov

Published by the AIP Publishing

\section{Articles you may be interested in}

Mathematical modeling of the process of filling a mold during injection molding of ceramic products

AIP Conf. Proc. 1683, 020112 (2015); 10.1063/1.4932802

Ceramic injection molding material analysis, modeling and injection molding simulation

AIP Conf. Proc. 1593, 582 (2014); 10.1063/1.4873848

Ballistic performance of porous-ceramic, thermal protection systems

AIP Conf. Proc. 1426, 84 (2012); 10.1063/1.3686227

Newly developed electron beam stepper for nanoimprint mold fabrication

J. Vac. Sci. Technol. B 28, 740 (2010); 10.1116/1.3449270

Rheological behavior of powder injection molding model slurries

J. Rheol. 36, 319 (1992); 10.1122/1.550348 


\title{
Rheological and Thermal Performance of Newly Developed Binder Systems for Ceramic Injection Molding
}

\author{
Berenika Hausnerova $^{\mathrm{a}, \mathrm{b}}$, Vera Kasparkova ${ }^{\mathrm{b}, \mathrm{c}}$ and Eva Hnatkova ${ }^{\mathrm{a}, \mathrm{b}}$ \\ ${ }^{a}$ Department of Production Engineering, Faculty of Technology, Tomas Bata University in Zlin, \\ Vavreckova 275, 76272 Zlin, Czech Republic \\ ${ }^{b}$ Centre of Polymer Systems, University Institute, Tomas Bata University in Zlin, \\ Trida T. Bati 5678, 76001 Zlin, Czech Republic \\ ${ }^{c}$ Department of Fat, Surfactant and Cosmetics Technology, Faculty of Technology, \\ Tomas Bata University in Zlin, Vavreckova 275, 76272 Zlin, Czech Republic
}

\begin{abstract}
In a novel binder system, carnauba wax was considered to replace the synthetic backbone polymers (polyolefins) enhancing the environmental sustainability of Ceramic Injection Molding (CIM) technology. The paper presents comparison of the rheological performance and thermal behavior of the aluminum oxide CIM feedstocks based on a binder containing carnauba wax with those consisting of a commercial binder. Further, acrawax (N, N'-Ethylene Bis-stearamide) has been considered as another possible substitute of polyolefins. For both proposed substitutes there is a significant reduction in viscosity, and in case of carnauba wax based feedstock also in processing temperature, which is essential for injection molding of reactive powders. Thermal characterization comprised analyses of single neat binders, their mixtures and mixtures with aluminum oxide. The presence of powder lowered melting temperatures of all tested binders except of polyolefin. Further depression in melting point of poly(ethylene glycol) is observed in combination with polyolefin in the presence of powder, and it is related to changes in size of the crystalline domains.
\end{abstract}

Keywords: Ceramic Injection Molding, Binder, Differential Scanning Calorimetry, Viscosity.

PACS: 81

\section{INTRODUCTION}

Polymer binder allows shaping of ceramic powders via Ceramic Injection Molding (CIM). A typical binder consists of three components: main body, backbone (non-reactive during debinding process, keeping the shape of the part prior to sintering) and additive [1]. Wax (paraffin), as the main body component, is usually combined with thermoplastic backbone, which can be polyethylenes, polypropylene, poly(methyl methacrylate), poly(ethylene glycol) or ethylene-based block copolymers. The advantage of the two last mentioned backbone components is a good adhesion between binder and powder without need of its further improvement using surfactants as stearic or oleic acids [2].

Successful injection molding of powdery materials requires preparing a feedstock whose individual powder particles are fully lubricated with the smallest effective amount of a binder. CIM powders are rather fine (from 0.1 to $5 \mu \mathrm{m}$ ) with an enhanced tendency to form agglomerates, therefore high shearing is necessary during processing. Batch mixing is utilized with planetary or Z-blade mixers, while high volume productions are performed using twin screw extruders or specially designed shear rolls.

There is a substantial gap in the fundamental knowledge of the interaction mechanisms acting in CIM feedstocks, and thus the current trend is to buy ready to use feedstocks based on patented binder systems compounded with powders on demand. Recently, substantial effort has been put to investigate the role of particular binder components and their interactions with ceramic powders as well as mold channel walls as a base for development of a novel, environmentally friendly CIM feedstocks [3-5].

The results have shown that binders containing carnauba wax or acrawax as a substitute of low density polyethylene, exhibited superior debinding properties with gradual thermal extraction up to the late debinding stage. For studying the interactions and chemical mechanism occurring within the binder system, the components were substituted with their low molecular analogues. Specific interactions of the substitutes were evaluated using combined FTIR and analogue calorimetry. Highest cross interaction values suggesting strong interactions were obtained for analogues of PEG and acrawax [4]. The adhesion between binder system components, as well as 
binders, powders and the mold materials was investigated via contact angle analysis, and using acid base model, surface energies were evaluated [5]. Binders showed similar values with only exception of PEG and to some extent acrawax which both exhibited higher values of total surface energies and of their polar components, compared to other binders tested. Among the binder components studied, it has been found that the role of the surfactant might be substituted with carnauba wax, however the surface characteristic is not the only parameter which has to be considered when preparing feedstock with optimum properties. Therefore, in the paper presented, the rheological and thermal behavior of the novel proposed binders are evaluated and compared with the commercial feedstock in order to investigate their suitability for injection molding step of the CIM process.

\section{EXPERIMENTAL}

Highly compressive super-ground alumina $\left(\mathrm{Al}_{2} \mathrm{O}_{3}\right)$ powder MARTOXID MR 70 supplied by Albermarle Corporation (USA) with the specific surface area of the particles (BET) $6-10 \mathrm{~m}^{2} / \mathrm{g}$, bulk density $0.90 \mathrm{~g} / \mathrm{cm}^{3}$, green density $2.2-2.4 \mathrm{~g} / \mathrm{cm}^{3}$, and fired density $\left(1,600{ }^{\circ} \mathrm{C}, 2 \mathrm{~h}\right) 3.8-3.92 \mathrm{~g} / \mathrm{cm}^{3}$ was used in the presented study. The density of the alumina powder $\rho_{\mathrm{Al} 2 \mathrm{O}_{3}}=4.05 \mathrm{~g} / \mathrm{cm}^{3}$ was measured by UltraFoam $1200 \mathrm{e}$ Automatic Gas Pycnometer under nitrogen gas and served for a calculation of powder/binder ratio. The particle shape was obtained from scanning electron microscopy (SEM) and particle size distribution was provided by supplier, Figure 1.

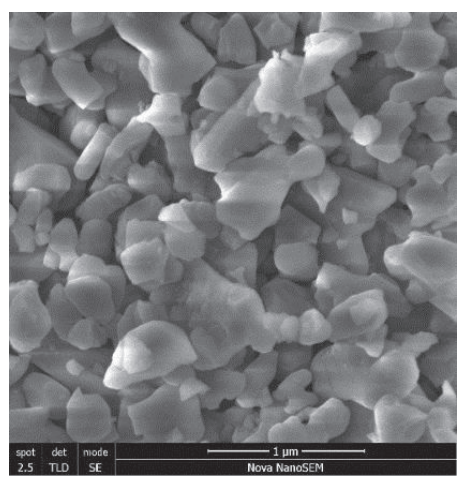

a)

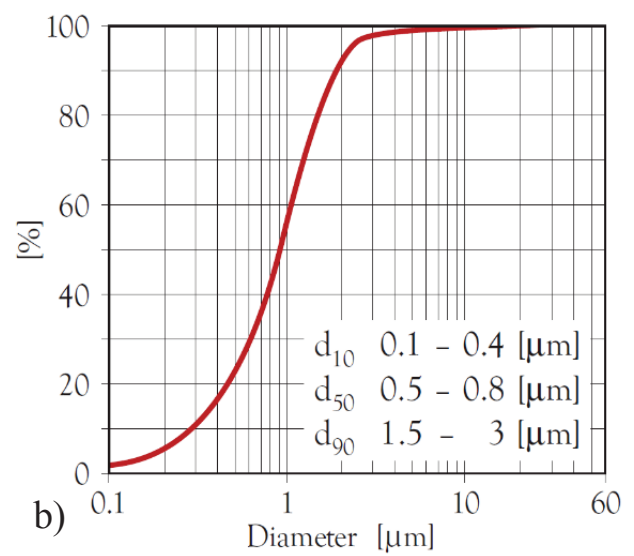

FIGURE 1. Alumina Powder (a) SEM of Particle Shape, (b) Particle Size Distribution

Binder A is commercially available, while the remaining two consist of paraffin wax (PW), poly (ethylene glycol) (PEG) and carnauba wax (CW, binder B) or acrawax (AW, binder C). In addition, all feedstock compositions employed in this work contain $1 \mathrm{wt} \%$ of surfactant.

Mixing of the $\mathrm{Al}_{2} \mathrm{O}_{3}$ powder (52 vol. \%) with three binder systems was carried out using a laboratory Z-blade mixer Brabender (Germany). The rotation speed of blades was set to $50 \mathrm{rpm}$ and mixing temperature was dependent on melting temperature of the particular components (binder $\mathrm{A}-160{ }^{\circ} \mathrm{C}$, binder $\mathrm{B}-90{ }^{\circ} \mathrm{C}$, binder $\mathrm{C}-150{ }^{\circ} \mathrm{C}$ ). Compounding feedstocks for 30 min was sufficient to obtain a steady mixing torque.

Rheological behavior of feedstocks based on fixed amount of alumina powder loading ( 52 vol. \%) and three different binder systems was determined using a capillary rheometer Gottfert 50 (Germany) with the capillary die (20/1) at three different processing temperatures suitable for a given binder system in a shear rate range from 35 to 1000 1/s. Activation energy was calculated according to Arrhenius equation at apparent shear rate of 1000 1/s.

Melting temperatures $\left(T_{m}\right)$ were evaluated using Mettler Toledo DSC 1 (USA) from the $2^{\text {nd }}$ heating scan at the rate of $10^{\circ} \mathrm{C} / \mathrm{min}$ under nitrogen atmosphere.

\section{RESULTS AND DISCUSSION}

Figure 2 demonstrates flow behavior of three feedstocks obtained at their processing temperatures. Binder system A, containing the commercial mixture, was compared with two new binder compositions $\mathrm{B}$ and $\mathrm{C}$ differing in backbone polymer $\mathrm{CW}$ and $\mathrm{AW}$, respectively. As it can be seen, in both novel binders, there is a significant 
reduction in apparent viscosity $\left(\eta_{a}\right)$, which can be suitable especially for micro injection molding. In all three cases, viscosity curves show an overshot at certain apparent shear rate $\left(\dot{y}_{a}\right)$, and as it can be noticed its onset is at higher temperature postponed to higher shear rate. Such complex flow behavior has been described in detail in our previous paper [6], where eight parameters model [7] to fit the data has been proposed and successfully applied. The model relates viscosity with shear stress and not shear rate because, as pointed by Lomellini and Ferri [8], for two phase materials the stress is continuous across the interface whereas the deformation rate is not.

Thermal behavior of the binder components as well as feedstocks was studied with Differential Scanning Calorimetry (DSC), which is also capable to assess their miscibility. Using this technique, a crystallization temperature or a depression of a melting temperature allow for obtaining information on the mixing. Changes in the peaks, namely shift of the melt/crystallization temperatures may disclose occurrence of interactions between binders; and between binders and powder.

Thermal characterization comprised analyses of single neat binders, their mixtures and mixtures with $\mathrm{Al}_{2} \mathrm{O}_{3}$ (Table 1). As PEG is the only hydrophilic binder component within all studied samples, it can be assumed that its miscibility with respective nonpolar binders (AW, CW, LDPE and PW) can significantly influence behavior of the feedstock under CIM. Therefore, mutual miscibility of PEG and the nonpolar binder in the presence of $\mathrm{Al}_{2} \mathrm{O}_{3}$ was determined as a part of the study.

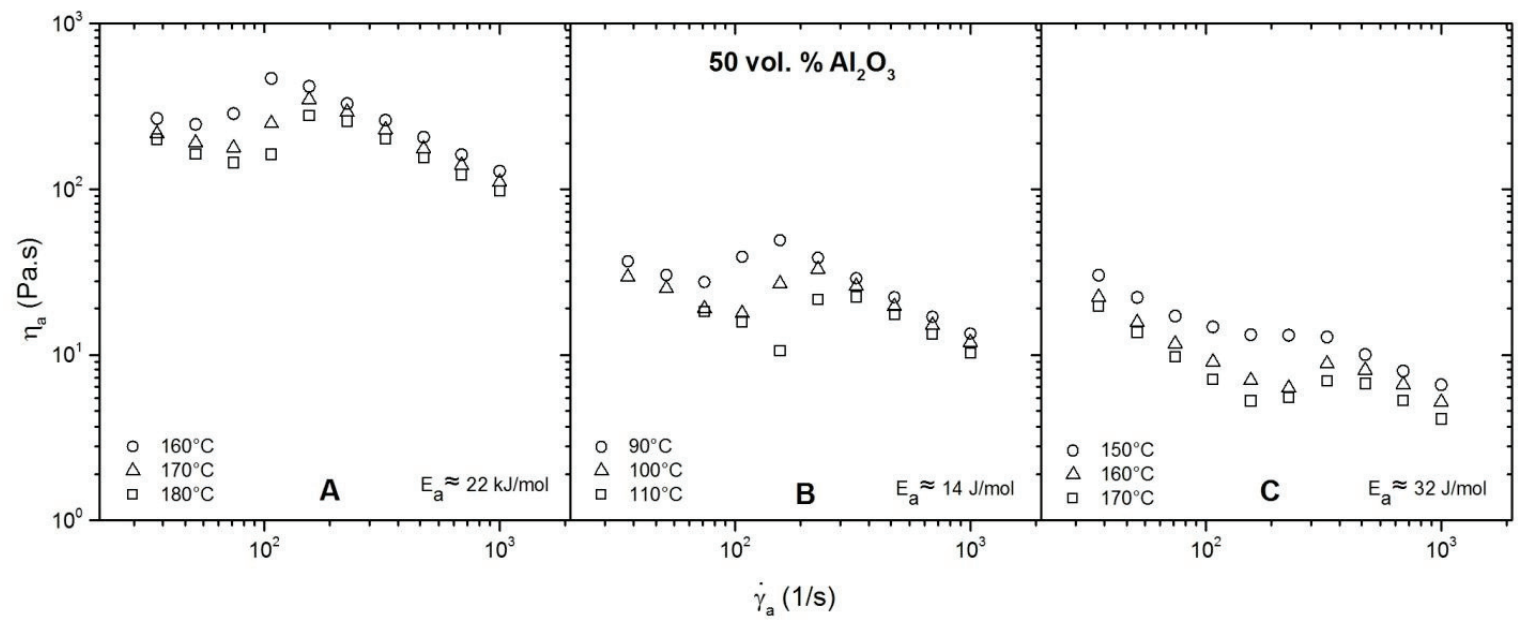

FIGURE 2. Flow properties of $\mathrm{Al}_{2} \mathrm{O}_{3}$ feedstocks containing commercial binder (A), and carnauba wax (B) and acrawax (C) based binders

The highest $T_{m}$ of about 144 and $104{ }^{\circ} \mathrm{C}$ showed AW and LDPE, then follows CW $\left(83.6{ }^{\circ} \mathrm{C}\right), \mathrm{PEG}\left(60.9^{\circ} \mathrm{C}\right)$ and the lowest $T_{m}$ of $54.5^{\circ} \mathrm{C}$ was recorded for PW. As regards course of melting, LDPE, PEG and PW exhibited single thermal event with melting occurring in a single peak; in case of PW a sign of peak split was recorded. On the other side, AW and PW melted in two steps, and in addition to main melting peak ( $T_{m}$ reported above), the second, well separated melting peak with lower $T_{m}$ was present (Table 1).

At first, effect of $\mathrm{Al}_{2} \mathrm{O}_{3}$ on the thermal properties of binders was evaluated. The DSC scans of $\mathrm{Al}_{2} \mathrm{O}_{3} /$ binder mixtures were compared to those of neat binders. Taking $T_{m}$ of the neat binder as a reference, in all cases, adding of $\mathrm{Al}_{2} \mathrm{O}_{3}$ lowered melting temperature. The shift was most pronounced for $\mathrm{PEG} / \mathrm{Al}_{2} \mathrm{O}_{3}$ with decrease of $2.8{ }^{\circ} \mathrm{C}$. Surprisingly, no change, on the other side, was observed for LDPE/ $\mathrm{Al}_{2} \mathrm{O}_{3}$. The effect of the ceramic powder on the melting temperature reduction can be related to the fact that the dispersed powder particles can hinder the mobility of the chains, whether it is polymer or wax, to such extent that they initiate reduction of their crystalline domain and thus cause melting point depression.

In the next step, changes of melting behavior of $\mathrm{PEG} / \mathrm{Al}_{2} \mathrm{O}_{3} /$ binder were evaluated. When inspecting DSC scans, these mixtures behaved in different way upon heating. Samples containing PEG, $\mathrm{Al}_{2} \mathrm{O}_{3}$ and one of the binders (AW, CW or LDPE) showed two clearly separated endothermic peaks, one originating from PEG and the second from the respective binder. However, relatively to neat binders (and also to binder $/ \mathrm{Al}_{2} \mathrm{O}_{3}$ ), both the peaks were displaced. Performance of the mixture with PW was, however, completely distinct. In this case, the tree-component system showed single melting peak with $T_{m}$ of $57{ }^{\circ} \mathrm{C}$ and notable shift in melting relatively to both neat $\mathrm{PW}\left(54.5^{\circ} \mathrm{C}\right)$ and PEG $\left(60.9^{\circ} \mathrm{C}\right)$. This behavior points to miscibility of the later components. In this respect, $T_{m}$ of AW and $\mathrm{CW}$ in the 
respective mixtures decreased, namely of about $1.2(\mathrm{AW})$ and $1.4{ }^{\circ} \mathrm{C}(\mathrm{CW})$; oppositely, no melting point depression was observed in case of LDPE where $T_{m}$ increased relatively to the neat binder. In case of melting peaks originating from PEG, it is apparent that their $T_{m}$ in mixtures displaced to lower temperatures (Table 1) relatively to neat PEG. In the blend based on PEG/ $\mathrm{Al}_{2} \mathrm{O}_{3} / \mathrm{LDPE}$, the melting point depression of PEG was the greatest observed. In general, a decrease in $T_{m}$ in a blend can be caused both by morphological effects, such as decrease in lamellar thickness and by thermodynamic factors (inter-chain interactions, interactions with particular material, change in crystal size). It can be speculated that the observed depression in melting point can be related to changes in size of the crystalline domains of the binders, caused by the presence of the other components in the blends.

TABLE 1 Peak melting temperatures from the second DSC scan recorded for binders, their mixtures with $\mathrm{Al}_{2} \mathrm{O}_{3}$ and threecomponent mixtures of binder, $\mathrm{Al}_{2} \mathrm{O}_{3}$ and PEG. Melting temperature of PEG peak in three component mixture is in grey.

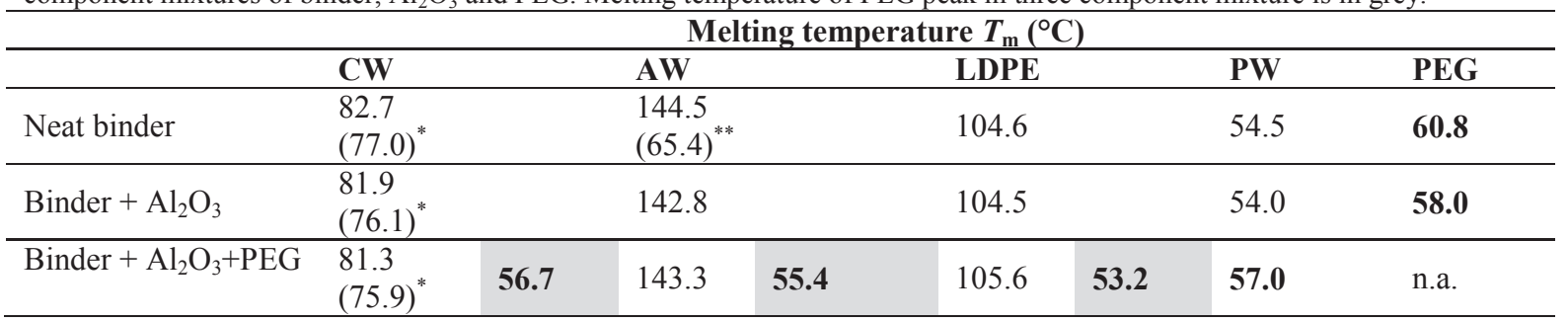

*) Partially split single peak **) Two melting peaks. In both cases minor peaks given in parentheses, n.a. not applicable

\section{CONCLUSION}

Similar flow cause was observed for all investigated feedstocks. At lower shear rates the viscosity of a feedstock decreases with increasing shear rate suggesting particle and polymer chains orientation and ordering with flow. When the shear rate reaches a certain value, particles cannot form layers and slide over each other, and flow turns into a dilatant. This structure restructuralization appears repeatedly as reflected in repeated changes between pseudoplastic and dilatant flow behavior. Nevertheless, both novel binders systems proposed showed overall lower viscosity than the commercial feedstock. Further, analysis of thermal behavior has shown that dispersed powder particles might hinder the mobility of the chains to such extent that they initiate reduction of crystalline domains. The melting point depression was the most pronounced in case of PEG binder component, while no change was observed for $\mathrm{LDPE} / \mathrm{Al}_{2} \mathrm{O}_{3}$. It is supposed that the further depression observed in melting point of PEG in combination with LDPE in the presence of $\mathrm{Al}_{2} \mathrm{O}_{3}$ can be related to changes in size of the crystalline domains.

\section{ACKNOWLEDGMENTS}

This work was supported by the Ministry of Education, Youth and Sports of the Czech Republic - Program NPU I (LO1504). Davit Bleyan, PhD is gratefully acknowledged for the performing the DSC measurements.

\section{REFERENCES}

1. R. M. German, Powder Injection Moulding, $1^{\text {st }}$ ed. Princeton: Metal Powder Industries Federation, 1990. p. 521.

2. B. Hausnerova, P. Saha, J. Kubat, T. Kitano, J. Becker., Journal of Polymer Engineering, 20(4), pp. 237-265 (2000).

3. D. Bleyan, B. Hausnerova, V. Kasparkova, V. Pata, Ceramics International, 42, pp. 460-465 (2016).

4. D. Bleyan, B. Hausnerova, P. Svoboda, Powder Technology, 286, pp. 84-89 (2015).

5. D. Bleyan, P. Svoboda, B. Hausnerova, Ceramic, International, 41, pp. 3975-3982 (2015).

6. B. Hausnerova, L. Marcanikova, P. Filip, P. Saha, Polymer Engineering and Science, 119, pp. 2925-2932 (2011).

7. P. Lomellini, D. Ferri, Proc. $13^{\text {th }}$ Int. Congress on Rheology, Cambridge, UK, 2000, pp. 118-120.

8. P. Filip, J. David, R. Pivokonsky, Acta Technica CSAV, 51 (4), pp. 349-362 (2006). 